\title{
Impact of ongoing COVID-19 pandemic on child health and well being
}

\author{
MD Abu Bashar', Nazia Begam² \\ From ${ }^{1}$ Assistant Professor, Department of Community Medicine, Maharishi Markandeshwar Institute of Medical Sciences and Research, Mullana, \\ ${ }^{2}$ Specialist Medical Officer, ECHS Hospital, Nararingarh, Haryana, India
}

\begin{abstract}
The pandemic of coronavirus disease-19 starting from Wuhan city of Hubei province in China has engulfed the entire world with adverse effects in terms of loss of human lives and stagnation in economies of most of the countries including the developed ones. One important aspect of this ongoing pandemic is its effect on children and their health round the globe. Apart from its direct effect in terms of morbidity and mortality caused by the illness itself, the indirect effect of the pandemic due to disruption of routine health services, closure of schools, isolation, and quarantining of the diseased and suspected persons, prolonged period of being indoors due to lockdown imposed by most of the countries which are having a more dreadful impact on children's health and psychological well-being, which is an alarming sign.
\end{abstract}

Key words: Child health, Coronavirus disease-19, Pandemic, Severe acute respiratory syndrome-coronavirus-2

A S cases of coronavirus disease-19 (COVID-19) surge worldwide and threaten to devastate life-saving health services, the survival of mothers and children is at a greater risk than any other group. Building on the lessons learned from previous outbreaks of Ebola virus disease and severe acute respiratory syndrome, Roberton et al. have estimated a devastating increase in the numbers of maternal and child deaths consequential from reductions in coverage of routine health services [1]. If left unchecked, these reductions due to disruptions in medical supply chains or the readiness of human and financial resources along with the declines in the uptake of health services by most of the communities in low- and middle-income countries (LMICs) are going to be more catastrophic for mothers and children than the direct effect of COVID-19 itself [2,3]. Moreover, the harmful effects of this pandemic are not going be distributed equally around the globe. They are expected to be most damaging for children in the poorest countries, and for those in already disadvantaged or vulnerable situations [3]. Roberton et al. have made projection of an additional 1.2 million child deaths and 56,700 maternal deaths in 118 countries if coverage of essential services drops by around $45 \%$ for 6 months, which is quite alarming [1].

The evidence has already started showing the negative effects of COVID-19 on maternal and child health. Children, in particular, are at risk not only of the infection, but also from losing or being separated from their parents and caregivers. Mothers and children

\section{Access this article online}

Received - 15 May 2020

Initial Review - 23 May 2020

Accepted - 19 June 2020

DOI: $10.32677 / \mathrm{IJCH} .2020 . v 07 . \mathrm{i} 07.001$ are being affected by the interruption of essential preventative and curative support and supplies resulting from indefinite suspending of services and transportation systems and due to financial constraints in view of stagnation in economies [2,3]. Constrained access to clinics, schools, social workers, water, and sanitation is a particular threat to the most vulnerable populations, and the lack of child protection and broader social services is particularly harmful to women and children in need of security and safety.

Looming above all of these problems is the economic impact of both the pandemic control measures being taken by the governments and the predicted knock-on effects of the projected global recession [4]. Reduced incomes, public and private debt, and reduced access to goods will affect many aspects of household health and nutrition. In brief, these effects threaten to reverse the hard-won progress that many LMICs have made in recent decades.

On May 12, 2020, United Nations Children's Fund (UNICEF) appealed for US\$1.6 billion to support its response for youngsters impacted by the COVID-19 pandemic, up from $\$ 651.6$ million requested during a similar appeal late March [5]. This increase reflects the devastating socioeconomic consequences of the disease and families' rising needs. As the outbreak enters its $5^{\text {th }}$ month, the prices for supplies, shipment, and duty of care are increasing dramatically.

"The pandemic may be a health crisis which is quickly becoming a toddler rights crisis," said by UNICEF executive Henrietta Fore. "Schools are closed, parents are out of labor, and families are under growing strain. As we start to reimagine what

Correspondence to: Dr. MD Abu Bashar, Flat No. 519, Trishla Plus Homes, Peer Muchalla, Zirakpur, Punjab - 140 603, India. E-mail: imback20006@yahoo.in

(C) 2020 The Author(s). This open access article is distributed under a Creative Commons Attribution (CC-BY) 4.0 license. 
a post-COVID world would appear as if, these funds will help us answer the crisis, get over its aftermath, and protect children from its knock-on effects."

Access to essential services such as health care and routine immunization has already been compromised for many children, which could lead on to a big increase in child mortality. Meanwhile, the psychological state and psychosocial impact of restricted movement, school closures, and subsequent isolation are likely to accentuate already high levels of stress, especially for vulnerable children [3]. According to an UNICEF analysis, around $77 \%$ of the children under the age of 18 worldwide, or 1.8 billion, are living in one of the 132 countries with some form of movement restrictions in place due to COVID-19 [5]. UNICEF is focusing its response to the pandemic on countries with existing humanitarian crises - working both to prevent transmission and mitigate the collateral impacts on children, women, and vulnerable populations, especially around access to health, nutrition, water and sanitation, education, and protection.

As a global community, UNICEF has identified six key areas of action and investment which require focus for overcoming the negative impacts of the pandemic [6].

First, children must be kept healthy and well nourished by providing supplies and protective equipment, which must reach health workers and affected communities. Concurrently, lifesaving maternal, new born, and child health services, routine vaccinations, and access to HIV treatment must be maintained.

Second, funding and support must urgently be prioritized for maintaining and strengthening water, sanitation, and hygiene. The combined work of governments and the private sector will be required to increase the practice of handwashing across the board, tapping into local innovation, and global partnerships.

Third, learning and connectivity among children must be maintained, and support must be given to governments to provide no technology, low technology, and digital solutions. Already before the crisis, UNICEF was working on an initiative with its partners [7] to extend digital infrastructure to ensure, all children can learn, no matter who and where they are, and this work needs to be brought quickly to much larger scale.

Fourth, parents and families must be recognized as essential front-line workers. They are needed to be supported through social protection measures that include cash and nutrition support. Fiscal response packages must target women and children. More than ever, everyone needs access to paid family leave, paid sick leave, and child-care.

Fifth, services to prevent and address gender-based violence - including counseling and support - must be designed and delivered. These services should be designated as essential and moved online as the current crisis makes women and children even more vulnerable to violence [2].

Finally, refugee and migrant children or children affected by conflict should not be forgotten. An effective COVID-19 response is one that includes all children in a country, whatever their status.

Many local initiatives have already begun, which are encouraging and appreciable [8]. These initiatives will push to consider the new opportunities that this crisis has created for communities to recover better, build stronger systems, and orient these services to reach all people globally.

This kind of long-term thinking could help prevent further loss of life from COVID-19 and would help reduce the effects of the global recession, while making progress toward healthier, equivalent, resilient, and sustainable future envisioned in the UN Sustainable Development Goals [9]. National programs should keep providing core maternal and child interventions even with the risk of COVID-19 transmission. Continued provision of these interventions is essential to save maternal and child lives [10]. Community-led sanitation programs could be the key to ensure healthy household environments and reducing undernutrition [11].

It is, therefore, important to learn from the data and transform this learning to invest in future-oriented solutions and plan a lasting recovery that could benefit children and communities for many years and decades to come.

\section{REFERENCES}

1. Roberton T, Carter ED, Chou VB, Stegmuller AR, Jackson BD, Tam Y, et al. Early estimates of the indirect effects of the COVID-19 pandemic on maternal and child mortality in low-income and middle-income countries: A modelling study. Lancet Glob Health 2020;8:e901-8.

2. United Nations. Policy Brief: The Impact of COVID-19 on Women; 2020 Available from: https://www.unwomen.org//media/headquarters/attachments/ sections/library/publications/2020/policy-brief-the-impact-of-covid-19-onwomen-en.pdf?la=en\&vs=1406. [Last accessed on 2020 May 15].

3. United Nations. Policy Brief: The Impact of COVID-19 on Children; 2020. Available from: https://www.unsdg.un.org/sites/default/files/202004/160420 covid_children_policy_brief.pdf. [Last accessed on 2020 May 15].

4. United Nations. Shared Responsibility, Global Solidarity: Responding to Socio-Economic Impacts of COVID-19; 2020. Available from: https://www. unsdg.un.org/sites/default/files/2020-03/sg-report-socio-economic-impactof-covid19.pdf. [Last accessed on 2020 May 15].

5. UNICEF Appeals for \$1.6 Billion to Meet Growing Needs of Children Impacted by COVID-19 Pandemic; 2020. Available from: https://www. unicef.org/press-releases/unicef-appeals-16-billion-meet-growing-needschildren-impacted-covid-19-pandemic. [Last accessed on 2020 May 15].

6. Fore HH. A wake-up call: COVID-19 and its impact on children's health and wellbeing. Lancet Glob Health 2020;8:e861-2.

7. UNICEF. UNICEF's Approach to Digital Health; 2020. Available from: https://www.unicef.org/innovation/sites/unicef.org.innovation/files/201811/ unicef $\% 27 \mathrm{~s} \% 20$ approach $\% 20$ to $\% 20$ digital $\% 20$ health $\% 20$ released $\% 20$ $22 \% 20$ oct $\% 202018$.pdf. [Last accessed on 2020 May 15].

8. UNICEF. Coronavirus Disease (COVID-19) Information Centre; 2020. Available from: https://www.unicef.org/coronavirus/covid-19. [Last accessed on 2020 May 15]

9. United Nations. Sustainable Development Goals; 2020. Available from: https://www.sustainabledevelopment.un.org/?menu=1300. [Last accessed on 2020 May 15].

10. Menendez C, Gonzalez R, Donnay F, LekeRGF. Avoiding indirect effects of COVID-19 on maternal and child health. Lancet Glob Health 2020;8:e863-4.

11. Akseer N, Kandru G, Keats EC, Bhutta ZA. COVID-19 pandemic and mitigation strategies: Implications for maternal and child health and nutrition. Am J Clin Nutr 2020;nqaa171. Doi: 10.1093/ajen/nqaa171.

Funding: None; Conflicts of Interest: None Stated.

How to cite this article: Bashar MA, Begam N. Impact of ongoing COVID-19 pandemic on child health and well being. Indian J Child Health. 2020; 7(7):286-287. 